\title{
A Morte e a Donzela, de Rogério de Carvalho: crítica genética, arquivo das artes performativas e a prática como pesquisa
}

ALEXANDRE PIERONI CALADO

Alexandre Pieroni Calado is engaged in a cross disciplinary project that, in the manner of a fictional historiography, attempts to recreate a play that the director, Rogério de Carvalho, never made with the texts from Princess Dramas: Death and the Maiden by Elfriede Jelinek. It is a project in which research is a vital component and that, as this text aims to demonstrate, can be set within the field of performance genetics. This essay will show prospectively that Calado's creative process has significant common aspects when compared with de Carvalho's poetic practice, in particular when considering working procedures with actors. Finally, we shall argue that there are relevant connections between genetic criticism/performance genetics, the theme of the archive in the performing arts and the problem of practice-as-research.

FICTIONAL HISTORIOGRAPHY / ROGÉRIO DE CARVALHO / GENETIC CRITICISM / PERFORMING ARTS ARCHIVE / PRACTICE-AS-RESEARCH

Só mostro que compreendi um escritor quando puder actuar dentro do seu espírito, quando o conseguir traduzir e alterar de diversas maneiras, sem reduzir a sua individualidade.

NOVALIS

INTRODUÇÃO: GENEALOGIA DE UM ESPECTÁCULO VIRTUAL

Alexandre Pieroni Calado virá a ter criado um espectáculo com o conjunto de textos para teatro Dramas de Princesas: A Morte e a Donzela, de Elfriede Jelinek, tendo por referencial as opções estéticas e os processos de encenação de Rogério de Carvalho, premiado director português cujo trabalho se tem desenvolvido em torno da relação dos actores com os mais relevantes dramaturgos modernos e contemporâneos. Depois do trabalho centrado na exploração de documentos fotográficos de um espectáculo do Teatro O Bando, em Pregação (2012), da investigação em torno 
de registos videográficos de um espectáculo do Teatro Praga, em Quarteto (2013), e da montagem desenvolvida a partir de textos de apoio do Teatro da Cornucópia, em Woyzeck 1978 (2014), trata-se aqui de replicar procedimentos de criação e de prosseguir horizontes estéticos de Rogério de Carvalho. Tendo Calado trabalhado como actor com este encenador em Tartufo (Companhia de Teatro de Almada, 2014) e tendo sido seu aluno na Escola Superior de Teatro e Cinema (2003-2004), o jovem encenador reconhece no veterano um profícuo ascendente. Mais, a linguagem do encenador angolano afigura-se ao encenador luso-brasileiro por demais meritória de referência; e de variações pessoais que prossigam o seu sentido de implacável rigor e de aposta na intensidade dos actores. ${ }^{1}$ Calado busca, então, utilizar materiais e meios de investigação historiográfica para apurar procedimentos e a linguagem de trabalho de Carvalho, tendo em vista uma apropriação produtiva destes e a sua aplicação numa nova criação.

Depois de ter trabalhado Georg Büchner e Heiner Müller, Alexandre Pieroni Calado prossegue o seu percurso na dramaturgia de língua alemã com a laureada escritora austríaca. Em Dramas de Princesas, Elfriede Jelinek trata de esfolar os arquétipos femininos. Nestes textos breves, marcados pela musicalidade e pela visualidade cinematográfica, pelo ritmo e por certa proximidade à prosa e ao ensaio, Jelinek expõe os mecanismos da linguagem que contribuem para a estruturação das identidades e relações sociais. Na medida em que a Donzela é uma figura que está, de certo modo, num pré-estágio da mulher e numa situação em que as coisas ainda não estão estabelecidas definitivamente, ela é o lugar por excelência dos conflitos envolvidos na produção de uma subjectividade feminina. Neste edifício em construção que é também uma ruína, Jelinek respiga os fragmentos da fantasia e do imaginário em transformação para nos lançar à cara os processos de sujeição e humilhação que se ocultam no nosso dia-a-dia. Este duplo movimento de jogo com a linguagem e de exposição dos interditos da parte de Jelinek permitiriam evocar aqui por razões análogas, mesmo que com estilos distintos, Jean Genet ou Howard Barker, autores por demais caros a Rogério de Carvalho. Com efeito, Jelinek é uma autora que já atraiu o interesse de Rogério de Carvalho, segundo testemunhou a sua amiga Anabela Mendes em conversa com Alexandre Pieroni Calado, em Maio

1 O presente texto é uma versão editada da comunicação apresentada no Colóquio Parcours de génétique théâtrale, realizado na Faculdade de Letras da Universidade de Lisboa, a 17-18 de Setembro de 2015, quando o projecto Dramas de Princesas: A Morte e a Donzela estava na fase inicial e não tinham começado ainda os ensaios. 
de 2015. Em resumo, na criação deste espectáculo, confluíram dois interesses que têm ocupado Alexandre Pieroni Calado nos últimos anos: os problemas do conhecimento imaterial das artes da cena e a encenação contemporânea de grandes textos em língua alemã para teatro.

\section{ELEMENTOS DE UMA MEMÓRIA FUTURA}

O espectáculo que teria a sua estreia a 18 de Dezembro de 2015, no Espaço Alkantara (Lisboa), no âmbito do Festival Temps d'Images, resulta de um aturado trabalho com uma pequena equipa de actores com quem Alexandre Pieroni Calado tem vindo a colaborar. Gostar-se-ia de mostrar, recorrendo a diários de ensaio e entrevistas a Calado, bem como a relatórios sobre o processo de trabalho de e entrevistas a Rogério de Carvalho, como a criação do espectáculo Dramas de Princesas terá decorrido segundo pressupostos e procedimentos que Calado elegeu do modus operandi de Carvalho. Tal não será seguramente alheio também ao facto de, neste grupo composto por Alexandra Viveiros, Gustavo Salinas Vargas, Paula Garcia, Sandra Hung e Sofia Dinger, Garcia e Hung partilharem com Calado um passado marcado por experiências profissionais com Carvalho. O primeiro indício da aproximação dos métodos de trabalho de Calado aos de Carvalho surge numa das páginas do diário de encenação de Calado, onde encontramos o seguinte esquema do faseamento do processo (Calado, 2015a):

SÍNTESE DO PROCESSO DE ENSAIOS DE DRAMAS DE PRINCESAS: A MORTE E A DONZELA. IMAGEM DIGITALIZADA DE CALADO (2015A), CADERNO CASTANHO NOTE, FOLHAS COSIDAS, B5, 30 FOLHAS

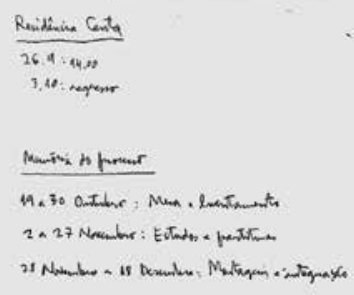

LATOARIa 6 set Setenteo sube Nownte.

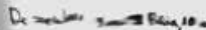

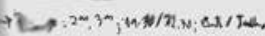
$\rightarrow$ Tom the trimenal tor patell. Pritima Rumoro: 29 November, 18 os 
É significativo assinalar que as etapas dos ensaios de Dramas de Princesas aqui registadas correspondem ao modo como Rogério de Carvalho organiza o seu processo de criação, como assinalam Lavínia Moreira (2007) e Laura Barbeiro (2007), que trabalharam como assistentes de Carvalho no processo de criação do espectáculo Fedra (Companhia de Teatro de Almada, 2006). O próprio Alexandre Pieroni Calado afirma recordar-se nestes termos da estruturação do processo de montagem de Tartufo (2014), dirigida por Carvalho, também com a Companhia de Teatro de Almada:

É uma divisão simplista mas corresponde a distintas ênfases que os ensaios foram adquirindo. Há, aliás, uma linha de continuidade com o que me recordo dos ateliês em que fui aluno do Rogério, em 2004-05. Trabalhando as cenas com autonomia, houve um progressivo apertar da malha, num vai-e-vem entre a mesa e a cena, do tom do espectáculo até à tensão de uma frase ou de uma pausa. Só no fim do processo é que ele montou as sequências e os primeiros corridos, fizémo-los só perto da estreia. (Calado, 2015b)

As palavras de Calado denotam um conhecimento experiencial da forma de operar de Carvalho, e as anotações do caderno de ensaios atestam uma vontade determinada daquele em replicar procedimentos deste último. Tal é possível sustentar, não apenas na organização geral do processo, mas também no próprio modo de trabalhar em cada uma das fases assinaladas. Na primeira, Calado parece investir em duas frentes simultâneas: a leitura e discussão da peça à mesa e uma compreensão in acto da peça realizada no curso da espacialização das cenas, ainda tendo os actores o texto na mão. Tal é a prática de Carvalho, como refere, por exemplo, Maria Manuela Rodrigues, a propósito da montagem d'Os Negros, no Teatro Nacional São João (2006): «[...] para Rogério de Carvalho a dramaturgia e análise do texto faz-se durante o levantamento da peça» (Rodrigues, 2006: 19).

Seguindo os protocolos de Carvalho com que contactou na Escola Superior de Teatro e Cinema, Calado utiliza improvisações, que nem sempre fazem uso da palavra, para encontrar esboços de acções físicas e de movimentações no espaço que permitem clarificar as situações propostas pelo texto e a importância relativa de cada acontecimento na economia geral da peça. Esta forma de conduzir a interpretação assume que são as acções físicas o suporte para a enunciação e, em particular, 
que é através delas que se conseguem localizar os movimentos virtualmente inscritos no texto. Ao mesmo tempo que delineia as situações, este primeiro levantamento que é realizado à totalidade do texto contribui para explicitar as personagens e as relações entre estas de uma forma em que a cena é o lugar privilegiado do pensamento. Se, por um lado, Laura Barbeiro observa que o primeiro levantamento realizado por Carvalho ajuda a acelerar o processo de memorização do texto pelos actores (Barbeiro, 2007: 8), Lavínia Moreira sustenta antes que Carvalho procura encontrar as tensões nas cenas e os temas nas personagens de forma que os actores se possam pôr em situação e credibilizar o texto literário (Moreira, 2007: 4-6).

Calado partilha este processo de trabalho em que uma discussão mais ou menos breve sobre o núcleo de cada cena, o seu desenvolvimento e pontos de viragem, serve uma compreensão elementar que é em seguida testada na cena e que contribui para uma aproximação verosímil à enunciação. Calado acrescenta: «Estamos diante de um método que remete a uma tradição que une Anatoli Vassiliev a Konstantin Stanislavski, passando por Olga Knebel: a análise activa como meio para chegar à voz do actor no jogo com a poesia» (Calado, 2015b). Este primeiro momento, por vezes designado por «levantamento do universo», é um espaço para o contacto colectivo com a peça e para um estabelecimento da visão geral do encenador. Pouco a pouco nesta fase estabelece-se o tom que caracteriza os espectáculos de Rogério de Carvalho, ritualístico e hierático, dominado pela contenção e cuidadosa composição da géstica e da movimentação no espaço, com uma aprimorada atenção à dimensão da palavra. Durante o período de ensaios que teria lugar em residência de criação na Companhia Olga Roriz (Lisboa), Calado terá buscado uma aproximação ao espírito e sentido de trabalho de Carvalho que não virá ter sido sem consequências para o resultado materializado no espectáculo que teríamos tido a possibilidade de ver em Dezembro de 2015.

A fase seguinte, de estudos, constitui o próprio núcleo do processo de trabalho e é talvez uma das fases mais difíceis de descrever devido ao seu intenso dinamismo e especificidade. O estudo do guião de trabalho do actor Alexandre Pieroni Calado da peça Tartufo, dirigida por Carvalho, reitera a dimensão turbulenta desta segunda etapa de ensaios. Por exemplo, junto às páginas relativas à Cena 1 do III Acto, podemos ver três esquemas da movimentação dos actores no espaço, dois deles rasurados, delineando diversas rotas de aproximação e fuga entre as personagens Cleanto e Tartufo; como sucederia com outros desenhos, 
nenhum destes veio a ser parte do espectáculo, vingando antes uma forma estática concentrada na acção verbal, em que as duas personagens levam a cabo, lado a lado, um duelo de palavras (Calado, 2014).

Seguindo a prática de Carvalho, no início desta segunda fase dos ensaios de Dramas de Princesas, Calado terá vindo a investir em algumas repetições do primeiro levantamento realizado, assim permitindo aos actores uma integração do texto e das orientações de encenação. Rapidamente, porém, as estruturas estabelecidas na primeira fase terão sido abandonadas, numa interpelação constante aos actores pela sua contribuição criativa e expressiva. Trata-se de um modo de trabalho que toma a cena como lugar de experimentação e que apenas aí afere a pertinência de uma leitura, a força de um desenho, a intensidade de um momento. ${ }^{2}$

Imobilidade. A imobilidade é o momento em que o actor escuta interiormente a ressonância do que realizou e as infinitas possibilidades que o seu corpo pode realizar (Rodrigues, 2006: 29). Desde que apoiada numa tensão, num movimento interior, é o que permite a concentração do trabalho no texto (Barbeiro, 2007: 25).

Monólogo interior da personagem. Teia de imagens, associações e afectos que contribuem para dar consistência subjectiva à situação que o actor vive em cena, que contribuem para o pôr em fluxo (Calado, 2015b). O encenador trabalha com o monólogo interior do actor, que se manifesta através das acções que este constrói ao nível vocal e físico (Rodrigues, 2006:30).

Plano. Uma importação da linguagem cinematográfica, que explora movimentações subtis, como rotações do eixo do corpo ou da direcção do olhar. A cada plano, corresponde um sentido (Moreira, 2007: 60). Podem ser frontais, laterais, diagonais, consoante o posicionamento do corpo do actor, em relação ao público (Barbeiro, 2007: 23). Está associado à direcção da atenção do espectador (Calado, 2015b).

Sonoridade da palavra. Além da dimensão semântica das palavras, a fonética, a rítmica e a energética carregam outra ordem de sentidos (ibidem). É fundamental fazer contrapontos e associações, gerir intensidades: não se pode trabalhar frases mortas: acabam por originar quebras de cenas. O problema não é a interpretação, é a escavação que tem de se fazer em relação ao texto, de modo que tenha música e seja entendido pelo espectador (Barbeiro, 2007: 29).

2 Aqui houve um problema com a memória do computador e por isso se perdeu um trecho do texto da comunicação, tendo-se conseguido apenas recuperar fragmentos que dizem respeito a termos utilizados, crê-se, por Rogério de Carvalho. 
Partitura. A composição dos elementos que o actor encontra na busca das acções físicas e vocais (ibidem: 22). Pode compreender tanto elementos relativos à movimentação no espaço quanto gestos, movimentos das mãos, do rosto e do olhar (Calado, 2015b). Escala do trabalho de detalhe onde encenador e actor encontram e desenvolvem o microcosmos do actor (Eloy, 2006 : 50).

É lamentável que se tenham perdido os registos da fase mais rica e intensa do processo de trabalho, onde as iterações e variações do desenho inicial das cenas vão dando lugar à composição do espectáculo, segundo uma economia que atribui uma grande centralidade à relação dos actores com o texto. Fica por conhecer de modo rigoroso como Alexandre Pieroni Calado, seguindo os passos de Rogério de Carvalho, decompõe as falas, hierarquiza as orações, elabora o ritmo e a cor, valoriza os verbos e a pontuação, evita tanto a monotonia quanto o recorte excessivo do texto, como constrói as relações não pleonásticas entre o gesto e a palavra, como busca a ancoragem do que é dito nos impulsos interiores. Fica por saber exactamente como se engendram as tensões e as atmosferas que caracterizam os trabalhos de Rogério de Carvalho, cujo espírito Calado pretende ter conseguido recriar. Por outro lado, talvez não fosse possível registar devidamente um percurso marcado por reviravoltas e situações particulares cujo sentido muitas vezes apenas se revela com as pessoas implicadas, no espaço do trabalho de experimentação e busca da solução para as questões que as cenas e o espectáculo levantam. Por exemplo, Lavínia Moreira marca o início desse período de estudos, no processo de criação de Fedra dirigido por Rogério de Carvalho com a Companhia de Teatro de Almada (2006), com a afirmação: «Fiz o primeiro de uma infinidade de desenhos relativos à movimentação na cena 1 do I Acto [...]» (Moreira, 2007: 8). Com efeito, se algo se pode dizer do processo de trabalho de Calado que terá tido lugar já no espaço da Latoaria (Lisboa) nesta segunda fase, prosseguindo a replicação dos procedimentos de Carvalho, é que ele virá a ter sido marcado por trânsitos: da ilustração à estilização das tensões, da contenção do gesto à composição de imagens, da ênfase na clareza da articulação das ideias à elaboração do jogo musical e sonoro.

A fase final do processo de trabalho de Rogério de Carvalho corresponde, grosso modo, à organização global do espectáculo com atenção para o ritmo e as transições entre unidades, bem como para os elementos plásticos, luminosos e sonoros. Não surpreenderá, então, que se tenha assistido a uma terceira fase de trabalho na qual Calado se 
dedicou ao modo como se alinhavam as diferentes peças que compõem Dramas de Princesas. Além disso, terá sido necessário dar resposta à premissa estabelecida por Calado de que os actores não deixem a cena a partir do momento em que nela entrem, o que terá motivado o recurso a procedimentos que marcam o teatro de Carvalho, como movimentações abstractas e a composição de imagens de grupo tratando os corpos como silhuetas e cenografia. Afirma Lavínia Moreira: «Aproximavam-se as datas de apresentação e daí a necessidade de se medir a organicidade da montagem...» sem que isso comprometesse a continuação do «[...] trabalhar com estruturas abertas que permitem um leque mais rico de leituras na recepção do espectáculo» (Moreira, 2007: 30-31).

Terá sido neste espírito de construção de formas abertas que Calado conduziu a integração dos elementos plásticos do espectáculo, segundo a orientação minimalista e depurada que é marca de Carvalho. Encontraremos em cena, então, apenas cadeiras, dispostas no espaço segundo linhas de força ajustadas ao desenvolvimento das situações do espectáculo; o jogo de luz assume um papel importante na definição das atmosferas, em geral dominadas pela penumbra e por transições suaves de ambientes; e o espaço acústico tem uma presença discreta, ora contribuindo para a intensificação da tensão, ora pontuando um ou outro elemento da tessitura do espectáculo. Desta forma, os diversos elementos integram a composição cénica já depois do trabalho com os actores e o texto ter atingido um certo grau de maturidade, sem nunca competirem com a centralidade atribuída a estes últimos nem, contudo, simplesmente ilustrarem as situações ou assumirem um papel decorativo.

No programa distribuído à entrada da sala, o encenador Rogério de Carvalho Alexandre Pieroni Calado pergunta: «Como dizer este texto de Breyten Breytenbach ELFRIEDE JELINEK» e como «manifestar a carga poética que o tivrO AS PEÇAS transportam». [...] A resposta de Rogério de Carvalho Alexandre Pieroni Calado faz-se a partir de uma construção dialogante entre a musicalidade das palavras e a violência do que dizem, entre a liberdade da imaginação e o confinamento dos corpos na aridez do espaço, entre a auto-ficção instituída pela reconstrução dos factos e a projecção sobre a realidade contemporânea. Das fissuras da voz, do corpo e da escuta nasce um espectáculo que nos mergulha na Áfriea do Sut segregacionista EUROPA MODERNA e nos mostra a falência moral, social e política de um pá́s CONTINENTE. [...] Há um gosto pela palavra que reconhece o medo de a pensar, depois o cuidado de a escrever, e, por fim, o perigo de a dizer. Mas, 
afastando esse medo através de uma disposição que recusa artifícios e nos mostra, em todo o seu esplendor, a relação física que existe entre o pensamento e o som, o trabalho que Rogério de Carvalho Alexandre Pieroni Calado vai minuciosa e delicadamente construindo devolve à palavra o seu potencial de transformação. [...] A cada um deles, ACTORES E ACTRIZES, é entregue mais do que a tarefa de narrar, transformando a sua presença numa ritualização do próprio acto de interpretar. Cada um deles, no modo como vão deixando expostas as linhas que cosem a memória evocada pelo texto, vão-se deixando guiar por uma encenação que pensa as implicações da presença de um corpo num espaço. Uma presença que começa por ser física mas que depressa se percebe que se estrutura a partir do tempo e da música, do movimento e da imaginação. (Tiago Bartolomeu Costa, «Rogério de Carvatho Alexandre Pieroni Calado encena acreditando que as palavras salvam vidas», Público, 03.09.2014 18.12.2015)

O espectáculo Dramas de Princesas, de Alexandre Pieroni Calado, poderá ter sido assim resultado de um processo de trabalho e criação prosseguindo os mesmos protocolos utilizados por Rogério de Carvalho. Com efeito, certa verosimilhança desta crítica apócrifa está indexada ao facto de algo ter vindo a ganhar a consistência de um projecto poético na carreira de Carvalho, algo que permite, não sem algum excesso de confiança, afirmar como foi um trabalho que ainda virá a ser. Um espectáculo feito à maneira de Carvalho, no seu espírito, ainda que transformado, não deformado. Calado realiza um estudo genético da actividade criadora de Carvalho, utilizando a sala de ensaios para testar procedimentos e apurar conhecimentos incarnados, servindo-se da cena para apresentar os resultados da sua pesquisa na linguagem mesmo do teatro. Este projecto, portanto, põe-nos perante uma experiência de prática artística baseada na pesquisa, que interroga problemáticas relacionadas com o arquivo das artes performativas.

WORDS, WORDS, WORDS: CRÍTICA GENÉTICA, ARQUIVO DAS ARTES

PERFORMATIVAS E A PRÁTICA COMO PESQUISA

O projecto Dramas de Princesas ter-se-á servido de métodos da genética teatral e poderá contribuir para evidenciar certas imbricações deste campo de estudo com questões contemporâneas relativas ao arquivo e à investigação académica em artes performativas. $\mathrm{O}$ espectáculo que 
resultará deste projecto pode ter sido, na estreia, como descrito, mas pode ser que, na apresentação do dia seguinte, as coisas se tenham passado de um modo ligeiramente diferente, pois é conhecida a prática do encenador Rogério de Carvalho de continuar os ensaios durante a carreira; nota Lavínia Moreira na conclusão do seu relatório: «Em termos de método, Rogério de Carvalho surpreende pelo carácter efémero, volátil, que tem a marcação» (Moreira, 2007: 55). E, se a prática descrita não é exclusiva de Carvalho, nem do teatro contemporâneo, como nos mostra o estudo conduzido por Jean-Louis Le Brave (2009) das anotações de Vitez para as suas três versões de Electra, no caso de Carvalho, em particular, o estudo de um espectáculo poderá concentrar a nossa atenção no objecto performativo que se actualiza a cada encontro com os espectadores, mas empobrecerá a fruição e a apreciação de um processo de transformação que se prolonga para lá dos ensaios e atravessa a carreira do espectáculo. Sendo certo que devemos evitar os perigos da crítica biograficamente enviesada, não revelarão estes aspectos do trabalho de Carvalho a temeridade da afirmação de Patrice Pavis: «A análise não deve, de fato, se obrigar a adivinhar todas essas decisões e intenções [do encenador], ela se baseia no produto final do trabalho [...]» (Pavis, 2005: XVIII)?

Muito se tem escrito sobre a especificidade da linguagem cénica, discurso este nas origens do aparecimento do campo dos estudos teatrais na sua demarcação dos estudos literários. Mas, pelo menos em Portugal, pouca atenção tem sido dedicada à investigação dos modos operativos dos artistas nos ensaios, das linguagens de trabalho entre os elementos da equipa artística; em resumo, se alguma pesquisa se tem feito sobre a especificidade do texto espectacular, persiste uma perturbante lacuna no que se refere à dimensão poiética da criação teatral. A delimitação dos limites temporais da investigação, a própria definição do que constitui o antetexto de um espectáculo ou a quantidade dificilmente manuseável de informação relativa às tentativas e escolhas realizadas em sala de ensaios podem assinalar dificuldades específicas de uma crítica genética.

Porém, como pensar a diversidade de observações registadas pelas duas assistentes de encenação, Laura Barbeiro e Lavínia Moreira, ao longo de um mesmo processo de trabalho de Rogério de Carvalho? Talvez se tenha de admitir que a crítica genética está condenada, mesmo quando realizada em condições ideais, por observação directa e regular dos ensaios, acompanhada de um diálogo próximo com os artistas, 
a produzir resultados incompletos, enviesados e subjectivos. A constatação do carácter lacunar da crítica genética, contudo, não deve questionar a pertinência do empreendimento. Pois, tal como o crítico Tiago Bartolomeu Costa se serve de informações que recolheu sobre o material dramatúrgico e sobre as questões lançadas pelo encenador, seguramente que um conhecimento das teorias, mais ou menos explícitas, dos artistas, das suas relações de trabalho e, em particular, do modo como se desenvolve o processo de ensaios pode enriquecer a visão do espectáculo, como salienta Josette Féral (Féral, s. d.: 4). Sem dúvida as noções aqui mencionadas de «partitura», «plano», «monólogo interior», por exemplo, poderão contribuir para uma fruição apurada e uma análise mais refinada do trabalho de Carvalho.

Talvez o teatro partilhe a ontologia dos objectos performativos tal como é descrita por Peggy Phelan (1993:146-66); talvez, mesmo podendo o espectáculo repetir-se, seja sempre diferente. A ser assim, estar-se-á perante a necessidade de encarar o objecto teatral como essencialmente processual. Como mencionado, é conhecida no meio profissional a prática de Rogério de Carvalho de continuar a ensaiar e a fazer alterações mesmo depois da primeira apresentação pública. Deste modo, de Carvalho revela-se um encenador por excelência para problematizar de forma radical o próprio estatuto de obra acabada que o objecto teatral genericamente tende a manter instável. Além disso, a objecção do carácter lacunar da crítica genética e da dimensão especulativa deste projecto poder-se-ia, contudo, fazer também a qualquer empreendimento analítico que se debruce sobre um espectáculo, como sublinha Nikolai Pesochinsky em «O fim da crítica?»: «... por que é que diversos críticos vêem no mesmo palco, ao mesmo tempo, espectáculos diferentes? Porque é que lemos a acção desta ou daquela maneira? O que é que vemos e de que é que não nos apercebemos?» (Pesochinsky, 2006: 11) Talvez mesmo a crítica de obras esteja sujeita a muitas vicissitudes e malentendidos, em particular quando estas obras comprometem o uso das ferramentas tradicionais de análise. Assim sendo, pode ser que um dos contributos da crítica genética seja efectivamente sublinhar que um trabalho apresentado ao vivo e construído em relação com o público tenha por característica uma maturação incompleta. Talvez a crítica genética possa contribuir deste modo para a redistribuição do valor deposto na obra, devolvendo-o ao caudal movente da sua génese.

O projecto Dramas de Princesas é o quarto de um ciclo sobre arquivo das artes cénicas portuguesas que Alexandre Pieroni Calado iniciou em 
2011 com o projecto Pregação, sobre o qual escreveu noutro contexto (Calado, 2012). Como mencionado, este conjunto de trabalhos levou-o a desenvolver uma investigação com distintos traços deixados por espectáculos apresentados no país na última metade do século $\mathrm{xx}$. O pressuposto comum aos diversos trabalhos deste ciclo é o de que é possível uma aproximação a um espectáculo e à poética de um encenador ou colectivo através dos materiais existentes no que Diana Taylor chama de «memória de arquivo»: «Archival memory exists as documents, maps, literary texts, letters, archaeological remains, bones, videos, films, CDs, all those items supposedly resistant to change» (Taylor, 2003: 19).

No trabalho acima discutido, Calado trata de utilizar vestígios de processos de encenação como material para activar problemas e forças levantados pela prática artística de Rogério de Carvalho, deles se apropriando para desenvolver um novo processo de criação. Nessa investigação, Calado e a equipa foram ainda influenciados pelas experiências pessoais que alguns deles haviam tido com o encenador angolano, por aquela outra dimensão do conhecimento performativo preservado que Taylor denomina de «repertório»:

The repertoire, on the other hand, enacts embodied memory: performances, gestures, orality, movement, dance, singing - in short, all those acts usually thought of as ephemeral, nonreproductible knowledge. Repertoire, etymologically "a treasury, an inventory", also allows for individual agency, referring also to "the finder, discoverer", and meaning "to find out". The repertoire requires presence: people participate in the production and reproduction of knowledge by "being there", being a part of the transmission. (Taylor, 2003: 19-20)

Taylor propõe este conceito de repertório não sem uma certa intenção de legitimar os conhecimentos incarnados, que entende sofrerem desatenção face aos passíveis de registo escrito e documental. Como saberão os condutores de bicicleta e de automóvel, há uma ordem tácita do conhecimento que se inscreve nos corpos e que se transmite de um para um como uma chama que acende outra. Como nota Taylor, a carne preserva estas memórias sempre com um grau de inexactidão que as transforma, mas, pelo próprio estudo destas alterações, pode acompanhar-se o desenvolvimento de tradições e identificar influências. Trata-se de um movimento que não é alheio à consciência de que há uma íntima relação entre o arquivo e a transmissão de conhecimento, a elaboração da 
memória comum e a construção de identidades. Ao pretender explorar o valor de uso destes materiais de arquivo existentes em centros de investigação, teatros e na rede mundial, atravessando-os da memória e dos testemunhos de pessoas que contactaram directamente com a prática de Carvalho, Calado tem pretendido movimentar memórias do arquivo documental e dos repertórios pessoais para o espaço público e contribuir para o desenvolvimento de uma memória partilhada, de forma crítica e eticamente comprometida.

Por outro lado, será difícil negar que há uma transposição necessária dos meios de simbolização quando se procura criar o arquivo de um espectáculo; mesmo um vídeo interactivo com múltiplos pontos de vista não pode preservar a sensação física do espaço e do movimento dos corpos, a temperatura das vozes. Também por isso tem Calado procurado fazer uma historiografia na qual a cena e a experiência teatral constituem o local e o momento de disseminação dos conhecimentos específicos das artes performativas. Não se terá tratado, portanto, de imitar um resultado, mas de procurar uma compreensão da poética de condução dos processos de criação teatral de Rogério de Carvalho, de lhe dar continuidade, desta fazendo emergir um começo.

Ainda que não tenha tido lugar no espaço propriamente académico, o projecto apresentado na secção anterior pode vir a ser inscrito no campo de actividades que a cultura anglo-saxónica genericamente designa por research-led-practice (prática orientada pela pesquisa) ou practice-as-research (prática como pesquisa) (Barrett e Bolt, 2010; Smith e Dean, 2009) e que na cultura francófona é designado por recherche-création (pesquisa-criação) (Gosselin e Le Coguiec, 2006). Como discutido por Alexandre Pieroni Calado noutro espaço, a emergência das questões relacionadas com a prática como pesquisa tem implicações decisivas para o estudo das artes performativas (Calado, 2009). Com efeito, nas últimas décadas, um pouco por todo o mundo, na Europa e no Reino Unido, na América do Norte e na Austrália, em particular, tem-se assistido a uma importante tomada de consciência quanto à especificidade da investigação realizada no domínio dos estudos artísticos. Esta tomada de consciência radicalizou a percepção da existência de conhecimentos próprios aos empreendimentos artísticos e coincidiu com a entrada das artes no ensino superior. Com o advento de pós-graduações, mestrados e doutoramentos no campo das artes, não apenas sob o ângulo da história e da filosofia da arte mas agora sob o da produção artística, as questões metodológicas assumiram um significado decisivo. Esta transformação 
do tecido académico contribui, então, para uma reafirmação da pertinência da crítica genética e para a prossecução da reflexão sobre os seus problemas. O projecto Dramas de Princesas pressupõe que o trabalho artístico é produtor de conhecimento, mesmo este sendo de natureza local, experiencial, muitas vezes tácita e incarnada. Evidenciou-se como o uso de diários e de registos de ensaios, bem como de entrevistas e de textos de artista, pode ser útil para o conhecimento e a compreensão do processo de trabalho de um encenador, e poder-se-ia facilmente argumentar sobre a relevância destes materiais em contextos pedagógicos e de investigação em artes.

Destacaram-se alguns aspectos da pesquisa em estúdio projectada por Alexandre Pieroni Calado no processo de criação do espectáculo Dramas de Princesa, através da recriação de procedimentos e da apropriação da linguagem de trabalho de Rogério de Carvalho. Neste trânsito textual, foram estes mesmos elementos do pensamento artístico de Carvalho que se salientaram, à semelhança do que terá vindo a suceder com o objecto cénico, ele mesmo reflectindo opções estéticas do encenador luso-angolano. Tratou-se, portanto, de apresentar uma prática artística informada pela investigação, que assume a sala de ensaios como local de experimentação com protocolos e vocabulários próprios das artes performativas. Uma prática de criação que se lança na tentativa de compreensão do modo como opera outro artista, trabalhando com conhecimentos relativos a esta forma de escrita na água que é o teatro. E que assume a própria cena como local e meio privilegiado para a disseminação dos resultados a que chega, entendendo que haverá certas dimensões do saber teatral que põem grandes dificuldades à tradução noutros suportes e linguagens. Arriscar uma criação tendo por base os traços de espectáculos e de processos ocorridos, tentar a descrição de um virtual inscrito numa série de possibilidades actualizadas pecará sempre pela perda da particularidade, dos problemas e soluções específicos que cada artista encontra. No entanto, talvez um estudo genético, cujos resultados são apresentados na própria linguagem do objecto que pretende investigar, apenas se sustente se carregar consigo a força do gesto inacabado que é própria ao que é o alvo da sua investigação.

Algumas das objecções ao projecto da crítica genética podem ser levantadas à crítica de arte, em particular à crítica das artes performativas. Qualquer tentativa de reflectir sobre a aventura artística poderá enviesar a fruição, mas será ingénuo pensar que não existem quaisquer conhecimentos a priori da parte do espectador a informar a recepção. 
De facto, os estudos genéticos dão visibilidade a um tipo de conhecimentos geralmente reservado a quem trabalha na sala de ensaios e no palco, além de que revelam imbricações com temáticas de redobrada relevância para os nossos dias. Acima de tudo, o trabalho com o projecto Dramas de Princesas, mais que analisar e discutir, procura lançar alguma luz sobre os modos da amizade, contribuindo para a construção de uma ideia do fazer artístico temperado pela suspeita face a ideias simplistas de autoria e de originalidade, valorizando antes linhas de influência entre gerações e promovendo um espaço público de rememoração e de projecção em colectivo.

\section{REFERÊNCIAS BIBLIOGRÁFICAS}

BARbeiro, Laura (2007), A Palavra como Acção, relatório de estágio do $3 .^{\circ}$ ano do curso de Teatro, Amadora, Escola Superior de Teatro e Cinema.

BARRET T, Estelle е BOLT, Barbara (2010), Approaches to Creative Arts Enquiry, Londres e Nova Iorque, I. B. Tauris.

CALADO, Alexandre Pieroni (2009), «PaR, PARIP e a investigação em artes cênicas», Anais da V Reunião Científica da ABRACE, São Paulo.

-- (2012), «Pregação - Actualizando possíveis de um espetáculo do século passado», Anais do VII Congresso da ABRACE, Porto Alegre - Rio Grande do Sul.

-- (2014), Texto cénico do espectáculo Tartufo, enc. Rogério de Carvalho, Companhia de Teatro de Almada. Documento policopiado, A4, $97 \mathrm{pp}$.

-- (2015a), Caderno castanho NOTE, folhas cozidas, B5, 30 folhas.

-- (2015b), Auto-entrevista conduzida pelo autor, documento áudio, 60 min, [inédito].

Costa, Tiago Bartolomeu (2014), «Rogério de Carvalho encena acreditando que as palavras salvam vidas», Público, 03.09.2014, http://www.publico.pt/culturaipsilon/noticia/rogerio-de-carvalho-encena-acreditando-queas-palavras-salvam-vidas-1668509.

ELOY, Miguel (2006), Um Espaço de Escuta, relatório de estágio de licenciatura em Teatro-Actores e Encenadores, Amadora, Escola Superior de Teatro e Cinema.

GOSSELIN, Pierre e LE COGUIEC, Éric (dir.) (2006), La recherche création: Pour une compréhension de la recherche en pratique artistique, Quebeque, Presses de l'Université du Québec.

FÉRAL, Josette (s. d.), «For a genetic approach to performance analysis», http://www.processusdecreation.uqam. ca/Page/Document/genetic_approach.pdf, [10.09.2015].

LE BRAVE, Jean-Louis (2009) «Can Genetic Criticism Be Applied to the Performing Arts?» in KINDERMAN, William e Jones, Joseph E. (ed.), Genetic Criticism and the Creative Process: Essays from Music, Literature and Theatre, Rochester, University of Rochester Press, Nova Iorque e Suffolk (Reino Unido), pp. 68-8o.

Moreira, Lavínia (2007), A Comunicabilidade da Obra Teatral, relatório de estágio da licenciatura em Teatro, Amadora, Escola Superior de Teatro e Cinema, 64 pp.

PAVIS, Patrice (2005), A Análise dos Espectáculos, São Paulo, Editora Perspectiva.

PESOCHINSKY, Nikolai (2006), «O fim da crítica?», Sinais de Cena, n. o 6, pp. 11-14.

PHELAN, Peggy (1993), Unmarked: The Politics of Performance, Londres e Nova Iorque, Routledge. 
RODRIGUES, Maria Manuela (2006), Os Negros: Memória da construção de um espectáculo, relatório de estágio de licenciatura em Teatro - Actores e Encenadores, Amadora, Escola Superior de Teatro e Cinema.

SMith, Hazel e DEAN, Roger (2009), Practice-led Research, Research-led Practice in the Creative Arts, Edimburgo, Edinburgh University Press.

TAYLOR, Diana (2003), The Archive and the Repertoire, Durham, Duke University Press.

\section{ALEXANDRE PIERONI CALADO}

Nascido em Lisboa em 1975, Alexandre Pieroni Calado é licenciado em Teatro pela Escola Superior de Teatro e Cinema (Instituto Politécnico de Lisboa), mestre em História e Filosofia da Ciência pela Faculdade de Ciências e Tecnologia da Universidade Nova de Lisboa e doutor em Artes Cénicas pela Escola de Comunicação e Artes (Universidade de São Paulo). Dirigiu Dramas de Princesas: A Morte e a Donzela (2015), Woyzeck 1978 (2014), Húmus: Tríptico\#2 (2014), Quarteto (2013), Pregação (2012), Mecânica das Paixões (2012), Tête de Meduse (2010), da beleza ou o sistema nervoso dos peixes (2009), e Miss Puss / Mestre Gato (2007). No teatro trabalhou com Ivica Buljan, Rogério de Carvalho, Amândio Pinheiro e Anabela Mendes, entre outros. É membro do Centro de Investigação em Artes e Comunicações (Universidade do Algarve / Instituto Politécnico de Lisboa). 